\title{
Discussion and group work design in O2O teaching of applied optics: questions, strategies and extending
}

Xiaotong Li, Zhaofeng Cen, Xiangdong Liu, Zhenrong Zheng

Xiaotong Li, Zhaofeng Cen, Xiangdong Liu, Zhenrong Zheng, "Discussion and group work design in $\mathrm{O} 2 \mathrm{O}$ teaching of applied optics: questions, strategies and extending," Proc. SPIE 10452, 14th Conference on Education and Training in Optics and Photonics: ETOP 2017, 104520Q (16 August 2017); doi: $10.1117 / 12.2265953$

SPIE Event: 14th Conference on Education and Training in Optics and Photonics, ETOP 2017, 2017, Hangzhou, China 


\title{
Discussion and group work design in $\mathrm{O} 2 \mathrm{O}$ teaching of applied optics: questions, strategies and extending
}

\author{
Xiaotong Li, Zhaofeng Cen", Xiangdong Liu, Zhenrong Zheng \\ State key laboratory of modern optical instrumentation, College of optical science and engineering, \\ Zhejiang University, Hangzhou 310027, P. R. China
}

\begin{abstract}
Applied optics course in Zhejiang University is a National Excellent Resource Sharing Course in China, and the online to offline teaching strategies have been implemented and shared with dozens of universities and colleges in China. Discussion is an important activity in teaching. In this paper our main consideration is designing the discussion questions and group works so as to develop the students' critical thinking, cooperative and sharing spirits, and communication abilities in the cosmopolitan era. Typical questions that connect different chapters and help the students to understand the relationship between each sub-system in both field of view and aperture are given for discussion. We inspire the students to complete group works such as ray trace programming by cooperation and then make presentations. All of these create a circumstance for sharing thoughts and developing intelligence and knowledge. A poll shows that the students pay more attention to optical design than before and have made progress in conversation and cooperation.
\end{abstract}

Keywords: Optics education, geometrical optics, applied optics, $\mathrm{O} 2 \mathrm{O}$ teaching, discussion, group work

\section{INTRODUCTION}

Applied optics in College of Optical Science and Engineering of Zhejiang University became a National Excellent Course in 2007, and a National Excellent Resource Sharing Course in 2016. All of our teaching resources including videos, PowerPoint files, flash files are also uploaded to the website http://www.icourses.edu.cn, and we have built the online test database at the website http://opt.zju.edu.cn/appopt .

We raise up the teaching level of Applied Optics with the development of online education in the world, especially with the springing up of Massive Open Online Courses (MOOCs) ${ }^{1}$ and the Small Private Online Courses (SPOCs) ${ }^{2}$. Now we were already in the era of "post-MOOC" ${ }^{3}$. In the project of optical education reform named "Sharing courses for the discipline of optical engineering in China" supported by the Sub-division of Teaching Guidance Committee of Education Ministry of China for the Engineering of Optics and Photonics, we have implemented as SPOCs for 3 years. In this project the main idea of teaching is still the constructivism learning theory put forward by Dr. Jean Piaget (1896-1980). He emphasized the activity of learners. In this theory, learning is considered as a constructive procedure based on the learners' original knowledge and experiences, and is completed in social culture interaction. This theory has been implemented in many courses ${ }^{4}$, and we presented our Online to Offline (O2O) teaching model based on the theory last year $^{5,6}$.

$\mathrm{O} 2 \mathrm{O}$ teaching is implemented in many aspects. In this paper our focus point is put on the $\mathrm{O} 2 \mathrm{O}$ discussion and group works. How to design the discussion, how to design the group works, and etc. This is connected with the idea of raising up the students' personality, such as critical thinking, cooperative and sharing spirits, communication and expression capabilities.

In the future, the globalization is a general tendency. Our students will work together with the partners comes from different cultural backgrounds. We hope that their inter-cultural communication abilities will be trained by the discussion and group works. It is much more important or has much more significant for the students in their career than only learning a course.

*cenzf@zju.edu.cn; phone (86)571-87952302; fax (86)571-87952302; opt.zju.edu.cn

14th Conference on Education and Training in Optics and Photonics: ETOP 2017, edited by Xu Liu,

Xi-Cheng Zhang, Proc. of SPIE Vol. 10452, 104520Q - @ 2017 ICO, IEEE, OSA, SPIE

CCC code: $0277-786 X / 17 / \$ 18 \cdot$ doi: $10.1117 / 12.2265953$

Proc. of SPIE Vol. 10452 104520Q-1 


\section{DISCUSSION DESIGN AND TYPICAL QUESTIONS}

\subsection{The idea and strategy of discussion design}

How to design the discussion, in our opinion it is based on the theory of Collaborative Learning or Synergetics that was put forward by Dr. Hermann Haken (1927- $)^{7}$. According to this theory, all systems in nature where there are life are open systems composed of many individual parts which interact with each other and can form spatial, temporal or functional structures by self-organization. The competitive, collaborative and symbiotic relationships exist at the same time.

The discussion design includes 2 parts, the first is to design the questions for discussion, and the second is to design organization style of discussion. The latter is also a part of group works, so we will describe it at the next chapter.

Using Haken's theory into teaching, the questions for discussion are designed according to the following:

(1) The common questions for everyone. From the standpoint of the students, they may encounter several types of questions. Some of the questions are common for everyone, especially at the beginning of learning the course. These are usually the basic questions that easy to be ignored by elder teachers and skilled students. They often constitute the foundation of the course, if not be answered a series of problems will appear. Some students may not be aware of these, so they need to be reminded by the questions.

(2) Some problems that will cause controversy or debate in the students are available for discussion. The debate makes truth clear, and is helpful in broadening idea and learning from different points of view. We suggest the students to discuss them, such as some optical systems are seemingly impossible according to the theory of the perfect optical systems, but actually can be designed. The preconditions of optical formulas are also available.

(3) The knowledge that the students will learn. A typical one is the relationship of finite aperture's diffraction and the resolution of optical systems. It does not belong to geometrical optics, but can lead the students to continue learning, and to be interested in studying physics optics in next semester.

(4) The questions that connect the knowledge of the different parts. There is an integrated geometrical optics knowledge system in our course. The imaging principles of each classical optical system are directly based on the theory of perfect optical system.

The questions are put forward continually with the learning progress on the website.

\subsection{Examples of typical questions}

According to the idea and strategies above, we give some typical questions for discussion as following:

(1) Common questions based on fundamental principles, for example:

Drawing is important in geometrical optics, but some of the students do not have the habit of solving problems by drawing. So we give the question: How do you understand that any known conjugate rays can be used as auxiliary rays?

If an object is at the infinite distance, whether or not it is only a point? The answer is simple, but many students think that the object at the infinite distance is a point. We ask the question to make the students think the relationship between length and angle. They discuss it in learning the theory of perfect optical systems and the beam limiting. This help the students to understand the objective height at finite distance and the field of view at infinite distance.

(2) Preconditions of formulas, for example:

Considering the formula of the total optical power or focal length of the system which consists of two optical groups in the air, if the system is not in the air, will the formula change? How to change it, and why? This question provides an angle of view to think about the absolute refractive index and relative refractive index. We encourage the learners to deduce a general formula and compare it with the optical power formula in the air.

The depth of view of different optical systems is also suitable for discussion. We deduce the description of depth of view and obtain its relationship with focal length, aperture and objective distance. It is applicable to photographic optical systems, but cannot be used in all optical systems. In contrast to the microscope, for the former, the shorter the focal length, the longer the depth of view. But the latter is a given conjugate-distance system, the greater the magnification, the shorter the focal length, and the shorter the depth of view. This discussion enable the students to apply the appropriate method depending on different environment. 
(3) The problems about the connection between relevant contents. Stop matching is a typical example. This can be discussed for 2 or 3 months. When establishing a perfect telescope, we put forward the problem: in Kepler telescope, when we increase the field of view in object space to a certain value, the image of the large field will disappear. If we add a lens at a certain place, the image of large field can be seen again. Why? Where this lens should be added? This gives the students a space for thinking, and some students solve it by doing experiments, but why? They cannot understand very well. When they learn the inverting lens in Kepler telescopes, they remember this problem again and finally understand the stop matching in the systems.

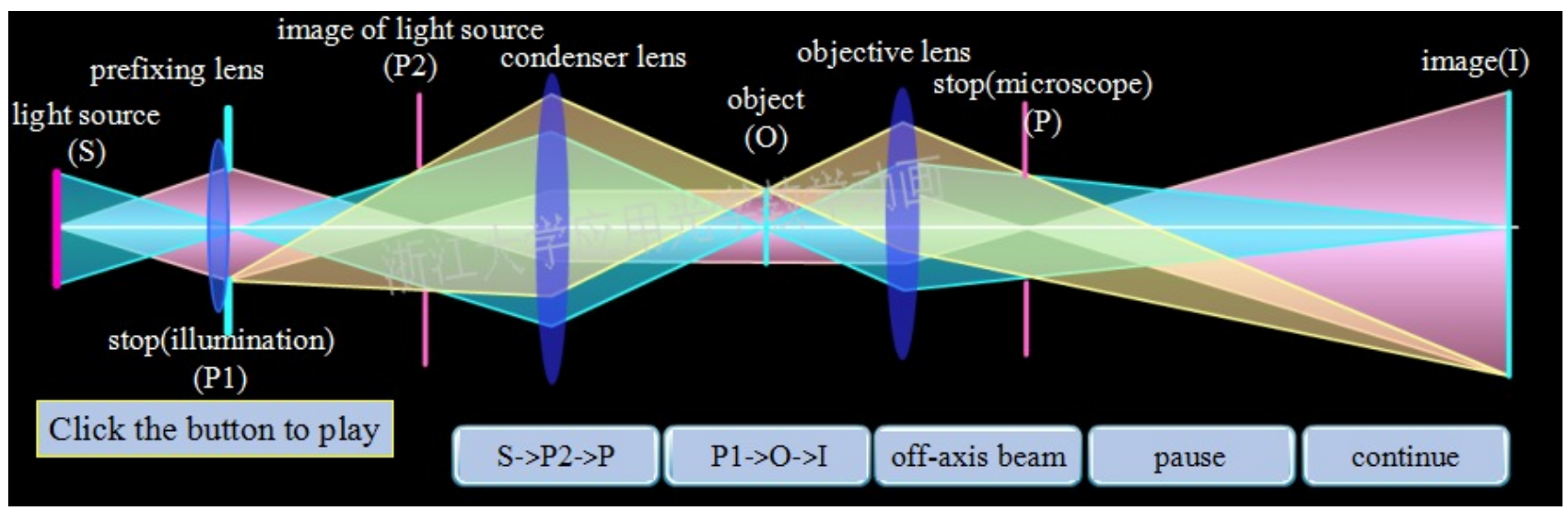

Figure 1. A flash of microscope and the illuminator

When learning microscope and its illuminator as shown in figure 1, the conversion between aperture and field stop in an imaging system and its illuminator is also an important topic for discussion. This is already presented as a hint when studying the concepts of aperture, pupil and field stop: considering a system composed of two sub-systems, if each subsystem has its pupil and field stop respectively, will the entrance rays be stopped in the combined system? Why? If some entrance rays are stopped, how to let them not to be stopped? What conditions should be satisfied if the imaging rays can transmit through sub-system 2 as well as they can transmit through sub-system 1? The discussion of this issue continues from spring semester to summer and attracts every study group.

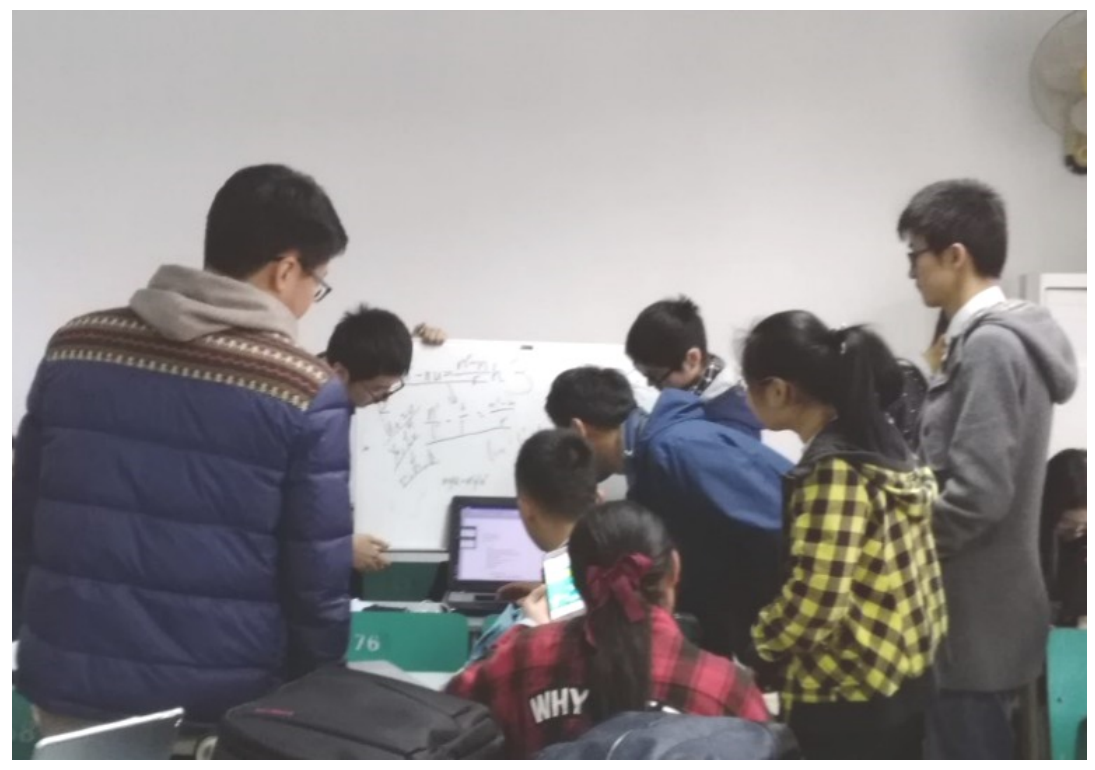

Figure 2. A study group is in discussion

Similarly, the question about reflective prism and parallel plate, and why we change the glass plates into air plates when we design an optical system including prisms or plates, these are the issues for continuing discussion. 
(4) The problems about the connection between relevant contents in our course or other courses are also considered, for example: what is the physical meaning of Lagrange-Helmholtz invariable and the relationship with sine condition? A perfect optical system cannot obtain the field of view of larger than $180^{\circ}$, but a fish-eye lens can do it? How to define the distortion of a fish-eye lens? Optical resolution is also a problem when learning the numeral aperture of microscopes and magnifications of telescopes.

As shown in figure 2, a study group is in discussion

\section{GROUP WORK AND ORGANIZATION}

\subsection{Programming and presentation}

Programming ability is very important in research of every field. Now optical design software is used widely, but it is helpful for the students of optical engineering to understand how to develop the optical or ray tracing software. Although they do not always work in the field of optical design, programming is a kind of activities for training computational thinking, and it is beneficial for them to do all sorts of work.

Applied optics is available for training computational thinking, so we encourage the students to develop a simple paraxial ray tracing program, finding focal length or calculating cardinal point positions, when they have studied the spherical optical systems and perfect optical systems. This work is completed by 2 students as a small group. Every small group present the program in the large group, and then the large group selects a small group as the representative to present the program in the class, as shown in figure 3.

Another small group work is to measure the focal length of a mobile camera. The work includes analysis of the errors. This is also completed by a small group of 2 students. The group works promote successfully the team spirit of our students.

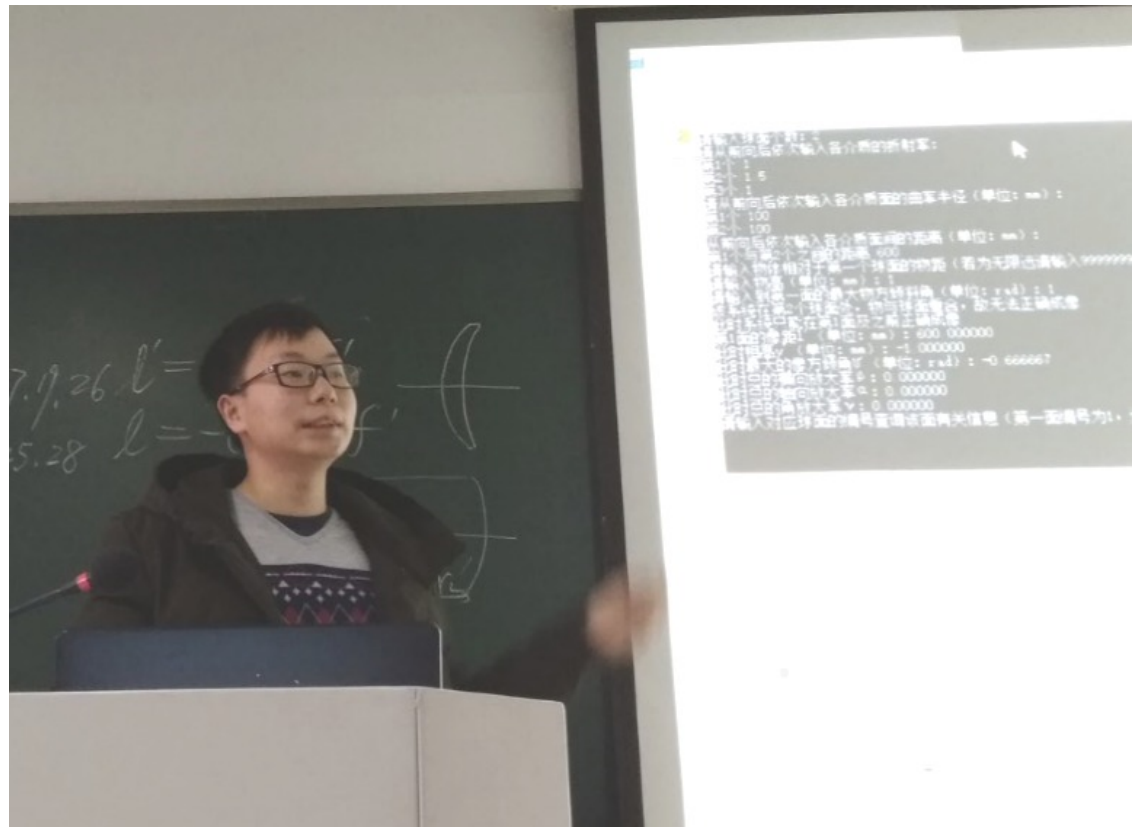

Figure 3. A group representative is giving a report about their programming

\subsection{On duty in QQ chatting}

In order to enhance the cooperation and sharing consciousness, we have established QQ group for chatting in each teaching class, in addition to offline discussion, the students are also encouraged in QQ group to ask their own questions. Some students often think their questions are too simple, and afraid to be laughed at by others, so they prefer to chat privately with the teacher to ask questions. After answering, we teachers encourage him to ask the same questions in QQ group and give the answer. This help them to set up self-confidence. 
Each teaching class has a large QQ group, at the same time we divide the students of each class into 5 or 6 study group, and let them on duty in the QQ group weekly. Every week the group on duty must ask some questions for the students to discuss. This allows students to pay attention to their own learning problems and often ask some questions that are concerned commonly.

These group works raise up the responsibility of each student.

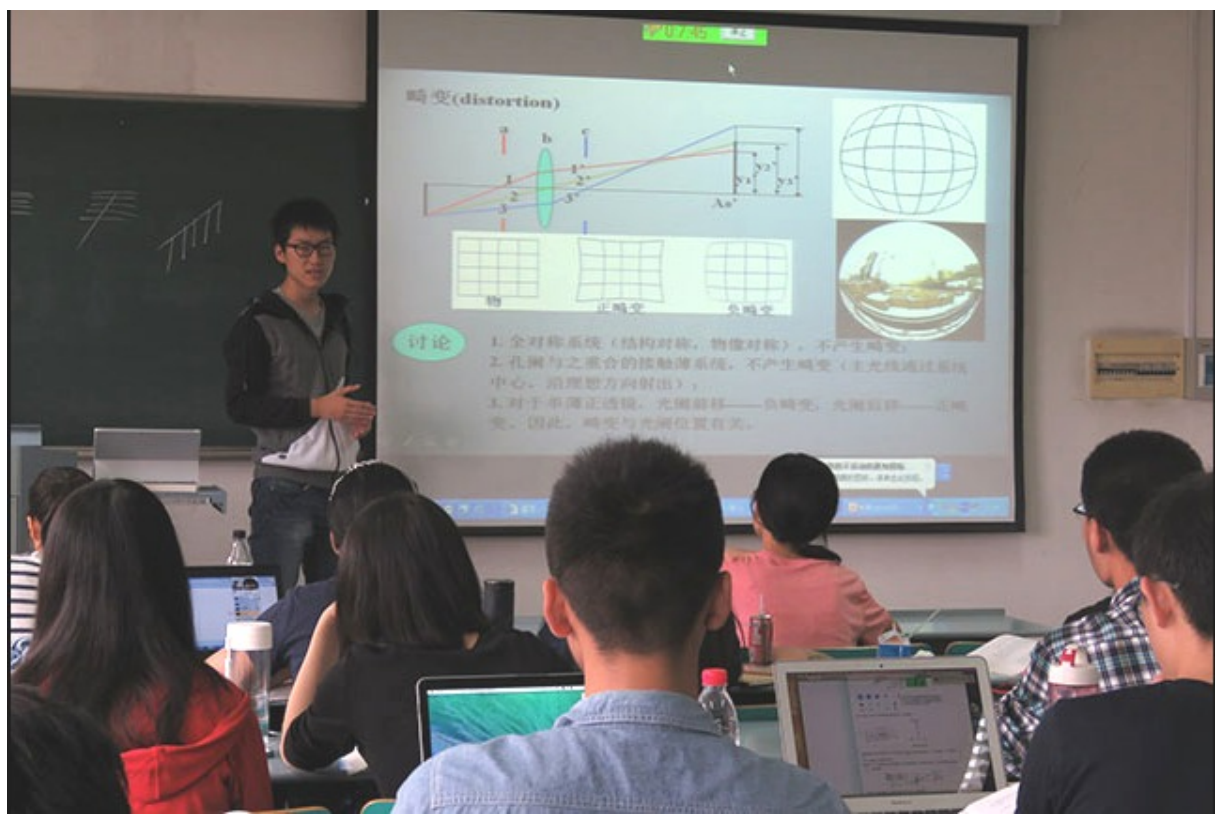

Figure 4. Flipped class: a representative of a study group is making his presentation about distortion

\subsection{Flipped class and role switching}

As written above, the students in one class are divided into about 5 study groups, corresponding to 5 kinds of aberrations: spherical aberration, coma, astigmatism and field curvature, distortion, and chromatic aberration. When studying aberrations, the students in one group self-study one or two kinds of aberration by watching online video, and then make a presentation to all of the students in one class as shown in figure 4. After the presentations, we give them a test about the aberration concepts and calculating using known data. The average score of each aberration will be tied to the corresponding group score.

This work flips the class and makes a role switching between the teachers and students, gives the students the chances to experience as teachers, and the chances to train their expressing abilities. Their presentation must be understood by others so as to obtain a good score for their group.

In our evaluation system, the scores of discussion and group works take a $15 \%$ proportion in the total score. The group leader will assign the group score to every member according to the member's contribution to the group activities.

\section{CONCLUSION}

Till now the $\mathrm{O} 2 \mathrm{O}$ discussions and group activities have been implemented for 7 years, and the new improvements have been made every year. The questions for discussion can come from students, but mainly condensed in the teaching process in many years, so the teacher must give more energy in teaching with good vocational spirit. As a result, the students have made remarkable progress in expressing their opinions, respecting others' opinions, raising up the selfconfidence and cooperation spirit, undertaking the team task, expressing ability and so on. In a poll last summer the students tended to give positive evaluation about themselves, and $92 \%$ of the students were willing to take the team work, and $97 \%$ of the students were satisfied with their group leader. In the subsequent short summer term, they paid more attention to optical design practice than before. 


\section{ACKNOWLEDGEMENT}

All the work in this paper is supported by the project of O2O Teaching Reform of Zhejiang University, the Sub-division of Teaching Guidance Committee of Education Ministry of China for the Engineering of Optics and Photonics (Sharing courses for the discipline of Optical engineering in China) and the project of Education Ministry of China (National Excellent Resource Sharing Course).

\section{REFERENCES}

[1] Tu, C. H., McIsaac, M., Doyle, R., Aydin, H. and Ozkul, A. E., "A cycle of online education ecstasy/agony: To MOOC or not to MOOC," Proc. IEEE Annu. Conf. Int. Counc. Educ. Media, 2013, 6820221 (2013)

[2] Sean, C., "Harvard plans to boldly go with Spocs, " BBC, 24 September 2013, $<$ http://www.bbc.co.uk/news/business-24166247> (30 April 2017).

[3] Kang, Y. Q., "An analysis on SPOC: Post-MOOC era of online education," Tsinghua Journal of Education, 35(1), 85-93 (2014).

[4] Jeanne, S. and Ahmad, A. H., "Design of learner-centered constructivism based learning process," Proc. of the Federated Conference on Computer Science and Information Systems, 2012, 1159-1164 (2012)

[5] Li, X. T., Cen, Z. F., Liu, X. D. and Zheng, Z. R., "The resource sharing course applied optics: flipped class model and MOOC-like construction," Proc. of the Third Teaching Symposium of the Discipline of Optical Engineering in China, 2014, (2014)

[6] Li, X. T., Cen, Z. F., Liu, X. D. and Zheng, Z. R., "Online to offline teaching model in optics education: resource sharing course and flipped class " Proc. of SPIE, 9946, 99460R (2016)

[7] Hermann Haken, "Visions of synergetics," Journal of the Franklin Institute, 334(5), 759-792 (1997) 